\title{
Caspase-mediated activation of PAK2 during apoptosis: proteolytic kinase activation as a general mechanism of apoptotic signal transduction?
}

\author{
Gary M. Bokoch \\ Departments of Immunology and Cell Biology-IMM14, The Scripps Research \\ Institute, 10550 N. Torrey Pines Road, La Jolla, CA 92037, USA. tel: 1619 784- \\ 8217; fax: 1619 784-8218; email: bokoch@scripps.edu
}

Received 22.12.97; revised 18.3.98; accepted 10.4 .98

Edited by S.J. Martin

\begin{abstract}
p21-activated kinase 2 (PAK2) is proteolytically cleaved during apoptosis through the action of DEVD-sensitive caspase(s). This cleavage event causes PAK2 activation, and PAK2 activity is implicated in regulation of the biochemistry and morphology of the apoptotic cell. PAK2 is just one example of a number of identified caspase targets that are protein kinases involved in regulating various aspects of cell function. We hypothesize that this may reflect their important role in regulating the controlled and orderly demise of the dying cell.
\end{abstract}

Keywords: p21-activated kinase; caspases; cell death; signal transduction

Abbreviations: PAK2, p21-activated kinase 2; JNK, c-Jun amino terminal kinase; FADD, Fas associated death domain; DAP-kinase, death-associated protein kinase; ERK, extracellular signal regulated kinase; MAP kinase, mitogen-activated protein kinase; MEKK1, mitogen/extracellular signal regulated kinase kinase kinase 1; FAK, focal adhesion kinase; DNA-PK, DNA-dependent protein kinase; CAM KII, calmodulin dependent protein kinase II

It is now generally understood that the process of regulated cell death plays a critical homeostatic role in a wide variety of cellular processes, ranging from basic organismal development to formation of the mature immune and nervous systems. All cells contain the machinery to undergo the regulated death response known as apoptosis (Jacobson et al, 1997; Ellis et al, 1991; Majno and Joris, 1995; King and Cidlowski, 1995). Apoptosis enables an organism to eliminate unwanted or defective cells through an orderly process of cellular disintegration that has the advantage of not inducing an undesirable inflammatory response. Apoptotic elimination of cells occurs during normal tissue development and turnover, as well as in a variety of pathological conditions. Indeed, growing evidence indicates that improper regulation of apoptosis contributes to disorders such as cancer, viral infection, autoimmune disease, neurodegenerative disorders, stroke, anemia, and AIDS (Wyllie, 1997). Understanding the underlying control mechanisms for apoptosis may therefore be of considerable therapeutic benefit.

The ability of an organism to maintain cellular homeostasis is critically dependent upon a balance between cell proliferation, differentiation and death. It is clear from our knowledge of cancer that uncontrolled cell proliferation can be harmful to the organism. It makes sense then that the processes involved in cell proliferation be tightly linked to the mechanisms involved with cell death, a concept supported by observations that genes involved in proliferation are also often capable of modulating or inducing cell death (Jacobson et al, 1997; Ellis et al, 1991; Majno and Joris, 1995; King and Cidlowski, 1995). In addition, recent evidence suggests that the critical role of the cytoskeleton in regulating cell proliferation signals may extend to the process of cell death as well (Meredith et al, 1993; Chen et al, 1997).

Apoptosis can be triggered by a wide variety of extrinsic signals (Fas ligand, tumor necrosis factor, growth factor withdrawal, kinase inhibitors, viral or bacterial infection, oncogenes, cytotoxic T lymphocytes, ceramide, UV irradiation, glutamate, heat shock, chemotherapeutic drugs, etc.) (Wyllie, 1997). Some apoptotic signals act in many types of cells (e.g., UV irradiation), while others are cell-type specific (e.g., glutamate). Some of these signals can induce either apoptosis or necrosis (e.g., TNF), while others may trigger apoptosis or mitogenesis (e.g., ceramide). While the reasons for these differences are unclear at present, a common cell death program or pathway exists; that is, a cascade of cellular events that is common from cell to cell, regardless of the initial death stimulus. There is substantial evidence for this, including the common and orderly morphological changes observed during all cell death and the existence of conserved genetic elements found in widely divergent organisms (e.g., the CED-3 proteases and CED-9: BCL-2 proteins in C. elegans and their equivalents in mammalian organisms) (Ellis et al, 1991; Martin and Green, 1995; Chinnaiyan and Dixit, 1996). Thus, even though the agents which initiate apoptosis vary from cell to cell, there appears to be a basic biochemical machinery underlying the process of regulated cell death.

The ICE/CED-3 caspases are ubiquitous and critical components of the cell death machinery. The caspases are a family of cysteine proteases with the distinctive property of cleaving immediately after aspartate residues (Chinnaiyan and Dixit, 1996; Whyte, 1996; Nicholson and Thornberry, 1997). Relatively few apoptotic substrates for 
caspases have been identified, and their exact roles in the execution of the apoptotic program remain unclear (Rosen and Casciola-Rosen, 1997). An emerging theme appears to be the identification of kinases as caspase targets. Many of these kinases are known to be involved in normal cellular signaling cascades that are important components of cellular growth andlor stress responses (Hunter, 1997).

\section{Kinases as caspase targets}

The activation of both tyrosine and serine/threonine kinases during apoptosis induced by a variety of stimuli has been reported (e.g., Eischen et al, 1994). Inhibitors of tyrosine kinases can block subsequent apoptotic events, while some kinase inhibitors (e.g., staurosporine) can be effective inducers of apoptotic cell death. In support of the critical role of protein phosphorylation events in apoptotic signaling, protein phosphatases also appear to be important modulators of apoptotic responsiveness (Morana et al, 1996; Sato et al, 1995).

Certainly, many of the kinases whose activity is stimulated by pro-apoptotic stimuli are acting as upstream signals which regulate the initiation of apoptotic death. Such upstream kinases include cJun amino terminal kinase (JNK), p38 MAP kinase, the ERK MAP kinases, and perhaps ceramide activated kinase (Chuang et al, 1997; Cosulich and Clarke, 1996; Mathias et al, 1991 and references therein). Activation of the ERK MAP kinase pathway correlates strongly with inhibition of cell death responses to growth factor withdrawal in neuronal cell lines (Xia et al, 1995) and to Fas receptor stimulation in Jurkat cells (Holmström et al, 1998). JNK has been shown to be stimulated through the action of a protein termed Daxx in 293 and Hela cells (Yang et al, 1997). Daxx is recruited and apparently activated through the death domain of the Fas receptor, and through its ability to stimulate JNK it acts cooperatively with the FADD pathway to induce apoptosis. Activation of the JNK pathway by small GTPases is also sufficient to induce apoptosis in Jurkat T cells (Chuang et al, 1997). In both cases, JNK activity can be shown to lie upstream of caspase activation. JNK activity antagonizes the anti-apoptotic effects of BCL-2 and may do so by phosphorylating BCL-2 directly (Park et al, 1997; Maundrell et al, 1997). JNK signaling may also enhance expression of Fas ligand, thereby initiating further death signaling through the Fas receptor (Hueber et al, 1997).

The ability of $\mathrm{Pl}-3$ kinase inhibitors to enhance cell death responses has suggested that the products of this lipid kinase regulate an anti-apoptotic mechanism. This has recently been shown to be mediated through the ability of $\mathrm{PIP}_{3}$ to regulate the serine/threonine protein kinase Akt. Activated Akt phosphorylates BAD and thereby prevents it from complexing: with and blocking the anti-apoptotic activity of BCL- $x_{\mathrm{L}}$ (Gajewski and Thompson, 1996; del Peso et al, 1997; Datta et al, 1997).

Death-associated protein kinase (DAP-kinase) is a $\mathrm{Ca}^{2+} /$ calmodulin-dependent serine/threonine kinase whose ectopic expression induced apoptotic death in a number of cell types (Cohen et al, 1997; Jin et al, 1997). Originally identified as a mediator of $\gamma$ interferon-induced cell death (Deiss et al, 1995), it has been established that the catalytic activity of this $160 \mathrm{kDa}$ kinase is required for its death-inducing properties. DAP kinase is associated with the actin cytoskeleton, and it has been proposed that DAP kinase provides a mechanism to link suppression of apoptosis to metastasis in turmor cells (Inbal et al, 1997). There is no indication that DAP kinase is a substrate for caspase-mediated proteolysis, and DAP kinase therefore may be a direct mediator of cell death responses to certain stimuli.

In contrast to the kinases that are acting upstream of the caspase cascades to initiate and/or regulate the apoptotic response, recent studies have established that the activation of a number of kinases occurs subsequent to the activation of the caspase cascades. Some of these kinases are activated indirectly through caspase action on other substrates, but an increasing number have been found to be directly cleaved by caspases, leading to modulation of their catalytic activity. Indeed, while the number of identified caspase substrates remains relatively small, a significant portion of these substrates turn out to be signaling kinases with an impressive array of cellular regulatory activities (Table 1 ).

\section{Caspase-mediated cleavage of p21-activated kinase 2 (PAK2)}

The p21 activated kinases (PAKs 1, 2, 3 or $\alpha, \gamma, \beta$, respectively) are a closely structurally related family of serine/threonine kinases whose activity can be regulated by the binding of the small GTPases Rac and Cdc42 (Manser et al, 1994; Knaus et al, 1995; Martin et al, 1995; Sells and Chernoff, 1997). PAKs are also members of a much larger family of signaling kinases related to the Ste20 kinase involved in pheromone responsiveness and polarized morphogenesis in budding yeast (reviewed in Sells and Chernoff, 1997). Mammalian PAKs have been implicated in the regulation of a number of cellular activities. These include regulation of MAP kinase signaling pathways (including JNK, p38 and ERK), the cell cycle, oxidant generation in phagocytic leukocytes, and cytoskeletal dynamics. Interestingly, a PAK-like kinase has also been shown to physically associate with the Nef protein of HIV, which is in turn capable of inducing apoptosis when overexpressed in Jurkat $\mathrm{T}$ cells (Cullen, 1996).

Cytoskeletal regulation by PAKs appears to be complex, requiring both the $\mathrm{C}$ terminal kinase domain and independent regulatory activities of the $\mathrm{N}$ terminus mediated through protein-protein interactions. PAK1 has been localized to areas of active membrane ruffling in fibroblasts, and the introduction of PAK1 mutants modified in the $\mathrm{N}$ terminal regulatory domain into cells induces membrane ruffling and polarized cell morphologies reminiscent of motile cells (Dharmawardhane et al, 1997; Sells et al, 1997; Manser et al, 1997). Indeed, PAK1 is abundant in the leading edge of oriented- or motile cells. These effects are largely independent of 
Table 1 Characteristics of kinases known to be proteolytically cleaved by mammalian caspases

\begin{tabular}{|c|c|c|c|c|}
\hline Kinase & Caspase site & $\begin{array}{l}\text { Consensus } \\
\text { phosphorylation }\end{array}$ & Substrates & $\begin{array}{l}\text { Regulatory } \\
\text { activities }\end{array}$ \\
\hline PAK2 & $\mathrm{SHVD}^{212}$ & {$[\mathrm{KRES} / \mathrm{T}]^{\mathrm{d}}$} & $\begin{array}{l}\text { p47 } 7^{\text {phox d }}, \text { MEK1 }^{f} \\
\text { myosin light chain }\end{array}$ & $\begin{array}{l}\text { Cytoskeleton, MAPK } \\
\text { pathways, NADPH } \\
\text { oxidase }\end{array}$ \\
\hline MEKKI & $\begin{array}{l}\text { GVED }^{871} \\
\text { DTVD }^{874}\end{array}$ & ND & MKK4 ${ }^{\mathrm{h}}, \mathrm{MEK} 1^{?}$ & MAPK pathways \\
\hline FAK & ND & {$[E D X X Y]$} & $\begin{array}{l}\text { Paxillin }{ }^{j}, \text { p130cas, } \\
\text { shc }\end{array}$ & $\begin{array}{l}\text { Adhesion; cytoskeleton, } \\
\text { nuclear signaling }\end{array}$ \\
\hline DNA-PK & $\begin{array}{l}\text { DEVD }^{2712} \\
\text { WVGD }^{2983}\end{array}$ & $\begin{array}{l}\text { [EPPLSQEAFA- } \\
\text { DLWKK] }\end{array}$ & $\mathrm{p} 53^{\mathrm{a}, \mathrm{b}}$ & DNA repair, cell cycle \\
\hline $\mathrm{PKC} \delta$ & $\mathrm{DMQD}^{330}$ & $\begin{array}{l}\mathrm{S} / \mathrm{TXK} / \mathrm{R}^{\mathrm{c}} \\
\mathrm{K} / \mathrm{RXS} / \mathrm{T}\end{array}$ & Many & $\begin{array}{l}\text { Pleiotropic signaling, } \\
\text { cytoskeleton }\end{array}$ \\
\hline PKC $\theta$ & $\mathrm{DEVD}^{354}$ & $\begin{array}{l}\mathrm{S} / \mathrm{TXK} / \mathrm{R}^{\mathrm{C}} \\
\mathrm{K} / \mathrm{RXS} / \mathrm{T}\end{array}$ & Many & $\begin{array}{l}\text { Pleiotropic signaling, } \\
\text { cytoskeleton }\end{array}$ \\
\hline PITSLRE & YVPD $^{393}$ & ND & (Cyclins)? & $\begin{array}{l}\text { Cell cycle, chromosome } \\
\text { segregation, } \\
\text { growth control }\end{array}$ \\
\hline PRK2 & ND & ND & ? & Cytoskeleton \\
\hline CaMKII & ND & $\begin{array}{l}\text { XRXXS/T' } \\
\text { XRXXS/TV }\end{array}$ & Many & Pleiotropic signaling \\
\hline Akt & ND & ND & BAD, others & Anti-apoptotic; mitogenic \\
\hline Raf-1 & ND & ND & MEK1, MEK2 & Mitogenic; antiapoptotic \\
\hline
\end{tabular}

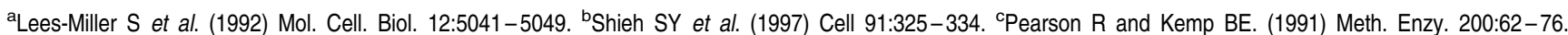

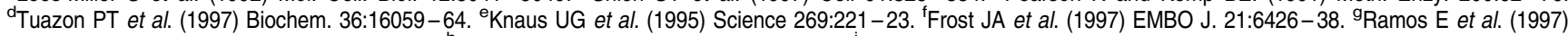
Receptors and Signal Transduction 7:99-110. hYan M et al. (1994) Nature 372:798-800. 'Burridge K and Chrznowsky-Wodnicka M. (1996) Annu. Rev. Cell. Dev. Biol. $12: 463-519$

PAK kinase activity, but do require intact proline-rich $\mathrm{SH} 3$ binding domains in the PAK $\mathrm{N}$ terminus. The ability of PAK to interact with components of mammalian and yeast signaling pathways through these SH3-binding domains has been demonstrated (Leeuw et al, 1995; Galisteo et al, 1996; Bokoch et al, 1996). Also relevant to their cytoskeletal regulatory function is the ability of PAKs to phosphorylate and modulate the activity of myosin. PAK and PAK-related enzymes phosphorylate the heavy chain of myosin from Acanthamoeba, thereby stimulating its actin-dependent $\mathrm{Mg}^{2+}$-ATPase activity (Wu et al, 1996; Brzeska et al, 1997). This effect has not yet been shown to occur with any mammalian myosins. PAKs, particularly PAK2, have also been found to phosphorylate the light chain of mammalian myosins in vitro, with a resulting increase in actin-dependent ATPase activity (Tuazon and Traugh, 1984; Ramos et al, 1997). The possibility that PAKs regulate the actinomyosin system of cells may explain much of the reported biological activity of PAKs.

Recently, several laboratories have shown that PAK2 is a substrate for proteolytic cleavage by DEVD-sensitive caspases during apoptosis induced by a variety of stimuli in different types of cells (Rudel and Bokoch, 1997; Lee et al, 1997). The $62 \mathrm{kDa}$ PAK2 is cleaved into a $34 \mathrm{kDa} C$ terminal fragment and a $28 \mathrm{kDa} N$ terminal fragment with a time course that parallels apoptotic death in Jurkat cells. In intact cells the cleavage is inhibitable by both Ac-YVADcmk and Ac-DEVD-CHO, but in apoptotic cell lysates the cleavage is at least 100 -fold more sensitive to DEVD inhibitors, indicating the involvement of a DEVD-sensitive caspase. This is supported by the ability of recombinant
CPP32/caspase-3 to cleave PAK2 in vitro. The closely related PAK1 and PAK3 proteins are not proteolytically cleaved under the same conditions.

PAK2 cleavage takes place adjacent to aspartate residue \#212, which lies in the region between the regulatory $\mathrm{N}$ terminus and the catalytic $\mathrm{C}$ terminus. Since removal of inhibitory constraints imposed by the $N$ terminus is thought to be involved in normal PAK activation by GTPases, the kinase activity of the PAK2 $C$ terminal fragment was evaluated in cells stimulated by Fas receptor crosslinking and was found to be constitutively activated. These data suggest that PAK2 may become a highly active kinase as a consequence of caspase-mediated cleavage (Figure 1). Moreover, the released $\mathrm{N}$ terminal fragment may itself be able to exert regulatory effects towards the cytoskeleton. However, it should be pointed out here that actual physical separation of the PAK2 fragments resulting from cleavage at Asp212 during apoptosis has not yet been demonstrated. It is possible that additional signals, e.g., binding of active Rac or Cdc42, are still necessary for PAK2 activation to occur in vivo.

PAK activity is implicated in regulation of at least two important processes which may contribute to the apoptotic death pathway. These conclusions were based on studies of stable Jurkat cell lines expressing an inducible kinase dead PAK1 (H83L, H86L, K299R) construct. Because of the high degree of sequence identity in the catalytic domains of PAK1 vs PAK2, this construct serves as a dominant inhibitor of both forms of PAK. Jurkat cells expressing dominant negative PAK1 (H83L, H86L, K299R) still underwent nuclear fragmentation and cell 


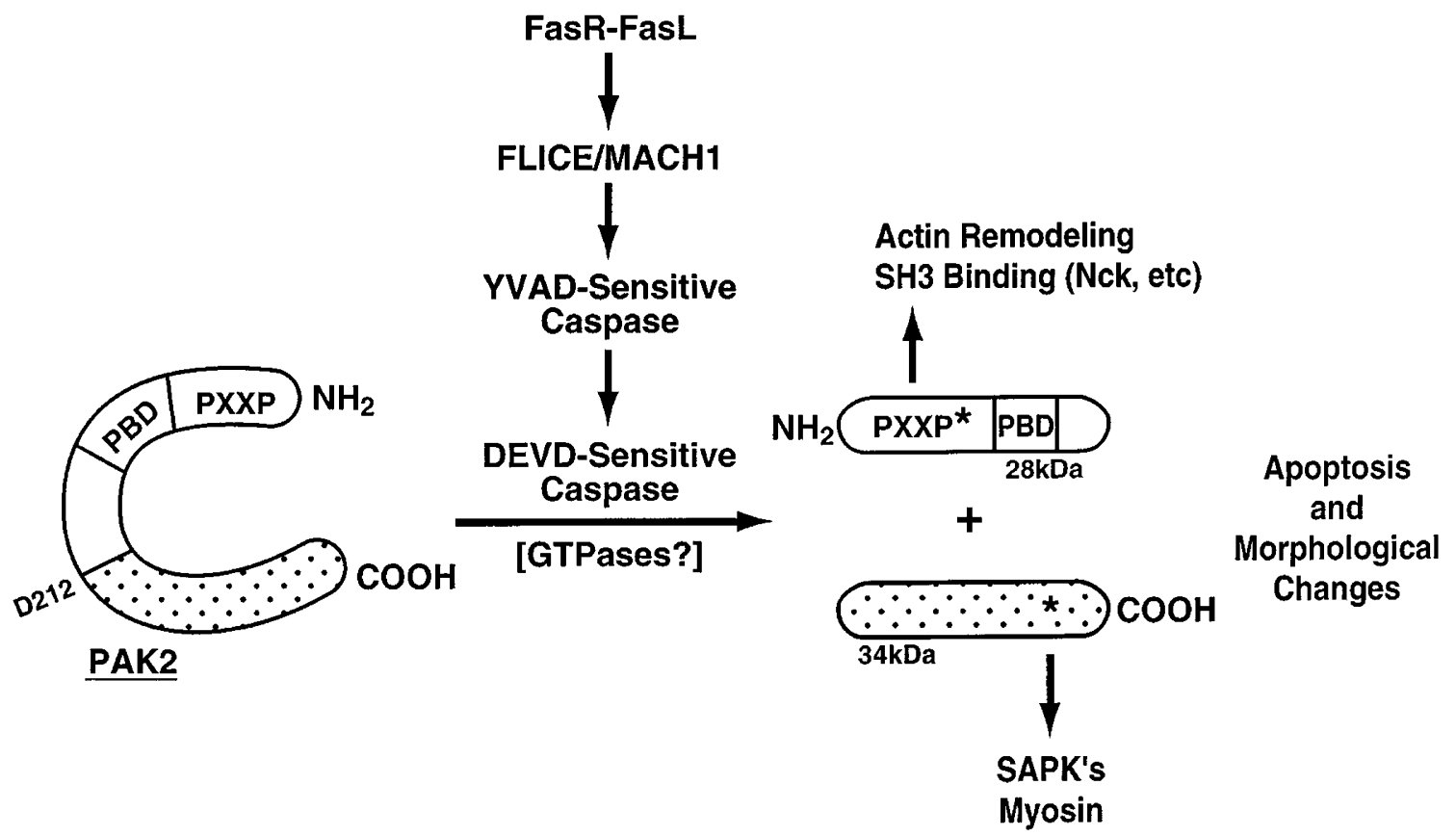

Figure 1 Schematic diagram indicating the likely activities of PAK2 activated due to caspase-mediated cleavage during apoptosis. The N-and C-terminal fragments formed may have distinct regulatory activities, as suggested by previous studies on PAK (see references). The possibility that activation post cleavage may require additional signals from Rac or Cdc42 GTPases requires investigation. PBD, p21-binding domain or GTPase-binding domain; PXXP, proline-rich SH3 binding domains in N terminus; D212 indicates the Caspase3 cleavage site on PAK2; SAPKs, stress activated protein kinases

death in response to Fas ligation; however the cells were inhibited in their ability to fragment into apoptotic bodies (Rudel and Bokoch, 1997). Phosphatidylserine exposure was actually enhanced in the same experiments, perhaps as a consequence of the blockade of cytoskeletal and morphological changes in these cells.

We observed that PAK function is required for the stimulation of the c-Jun amino terminal kinase (JNK) pathway by Fas in Jurkat cells (Rudel et al, 1998). JNK activation by Fas receptor is partially blocked by caspase inhibitors, as has been demonstrated with a number of other apoptotic stimuli as well. Expression of dominant negative PAK blocked Fas-induced activation of JNK, but did not affect activation stimulated by phorbol esters. Inhibition of JNK activity was not sufficient to block cell death induced by Fas receptor crosslinking. However, activation of the JNK pathway by Cdc42 (Chuang et al, 1997) or expression of the constitutively active PAK C terminus was sufficient to induce an apoptotic response, albeit with a time course that was much slower than that of Fas.

The proteolytic cleavage and activation of an endogenous PAK in Xenopus oocytes by caspases has also been recently reported (Saure et al, 1997). Interestingly, in this system PAK activity appeared to be anti-apoptotic, as the expression of a catalytically inactive PAK C terminal fragment induced cell death. This effect was suppressed by addition of BCL-2 or a DEVD caspase inhibitor peptide, and rescued by competing the dominant negative mutant with constitutively active PAK. The effects of PAK on cell death in the Xenopus system appear to be linked to effects of PAK to modulate cell cycle arrest.

Overall, these data suggest that PAK(s) play important roles in controlling membrane, morphological and signaling responses during apoptosis. This can be a result of an activation process distinct from the normal means of PAK regulation (i.e., the binding of activated Rac or Cdc42) that involves caspase-mediated proteolysis, although similar regulation through GTPase-regulated signals remains a possibility. While PAK2 appears to be one of the important downstream targets of caspase action, it now appears that it is not just an isolated example of a kinase regulated by caspase-mediated proteolysis. An increasing number of other kinases appear to be targets of apoptotic regulation via caspases as well.

\section{Other protein kinases proteolytically cleaved and regulated during apoptosis}

\section{MEKK1}

As mentioned above, the ability of certain apoptotic stimuli to induce signaling via the JNK and p38 MAPK pathways is dependent upon caspase-mediated events. This is also true during the process of anoikis, or apoptosis due to loss of integrin-initiated adherence signals (Frisch et al, 1996). One potential mechanism for activation of the JNK and p38 kinase cascades is through the recently described proteolytic activation of MEKK1 by caspases (Cardone et al, 1997). 
MEKK1 serves to couple multiple hormonal signals preferentially to activation of the JNK pathway in a variety of cell types. Full length MEKK1 has been recently cloned and shown to be stimulated by the small GTPases Ras and Rac/Cdc42 (Fanger et al, 1997). During anoikis of MDCK cells induced by cell-matrix detachment, MEKK1, which migrates as a series of $160-200 \mathrm{kDa}$ bands representing multiple phosphorylated states of the full length protein, was shown to be cleaved to fragments of $\sim 78 \mathrm{kDa}$ and $\sim 100 \mathrm{kDa}$. This cleavage was inhibitable by $\mathrm{CrmA}$, and was shown to occur with purified recombinant caspases-3, -7 , and -8 in vitro. Cleavage in apoptotic extracts was extremely sensitive to inhibition by Ac-DEVD-CHO, but less sensitive to Ac-YVAD$\mathrm{CHO}$. The proteolytic cleavage site was localized to aspartate residues within the sequence aa868-871 (GVED) and aa871-874 (DTVD). Since truncation at these sites would remove the regulatory $N$ terminus from the full length 1493 aa. MEKK1, activation of MEKK1 was predicted and shown to occur. Transient expression of the constitutively active Cterminal MEKK1 cleavage product induced apoptosis as assessed by the criterion of abnormal nuclear morphology, consistent with a prior report that MEKK1 was able to induce apoptosis, and the observation that dominant negative forms of MEKK1 inhibited apoptosis and anoikis (Johnson et al, 1996). Caspase-mediated MEKK1 cleavage and activation may thus contribute to nuclear changes during apoptosis and may enhance signals through the JNK pathway which promote cell death. MEKK1, as well as other stimuli which activate JNK (e.g., activated Cdc42), also increase caspase activity, suggesting positive feedback loops may exist which promote an apoptotic cascade.

\section{Focal adhesion kinase (FAK)}

It is a well established phenomenon that attachment of cells via integrins to extracellular matrix components such as fibronectin, vitronectin, and collagen has protective effects against apoptotis induced by other stimuli (Meredith et al, 1993). At least part of this protective effect appears to be due to the activation by adhesion of the tyrosine kinase known as focal adhesion kinase or FAK (Frisch and Francis, 1994; Hungerford et al, 1996). FAK localizes to focal adhesions and may regulate the formation of focal adhesion assemblies in spreading or migrating cells, as well as signaling pathways to the nucleus which suppress apoptosis and enhance proliferation.

FAK has been shown to be proteolytically cleaved during apoptosis induced by Apo-2L and/or Fas receptor crosslinking in both adherent and suspended Jurkat $T$ cells (Wen et al, 1997). Cleavage correlated with the time course of caspase-mediated PARP proteolysis, as well as with cell death. The intact $120-125 \mathrm{kDa} F A K$ is sequentially cleaved to an $85 \mathrm{kDa}$ product, followed by a $77 \mathrm{kDa}$ fragment. While both fragments were also observed in MCF-7 breast cancer cells, only the $85 \mathrm{kDa}$ fragment was detected in $\mathrm{H} 460$ non-small cell lung cancer cell line. Earlier reports had also demonstrated FAK cleavage during c-myc-induced apoptosis, and both FAK cleavage and apoptosis were inhibited by adhesion to fibronectin or collagen matrices (Crouch et al, 1996). Apo-
2L- and Fas-induced FAK proteolysis in intact cells was inhibited by $40 \mu \mathrm{M}$ ZVAD-FMK but not by YVAD-CHO at up to $200 \mu \mathrm{M}$. DEVD-CHO preferentially blocked formation of the $77 \mathrm{kDa}$ product, but also blocked formation of the $85 \mathrm{kDa}$ fragment at higher concentrations. In vitro studies indicated that cleavage to the $85 \mathrm{kDa}$ product was catalyzed by caspase-3 and caspase-7, while $77 \mathrm{kDa}$ product was formed in response to caspase-6, either from the intact FAK or from the $85 \mathrm{kDa}$ fragment. The initial cleavage generates a $33 \mathrm{kDa} C$ terminal piece containing an intact kinase domain and the $85 \mathrm{kDa}$ fragment which consists of the remaining $\mathrm{N}$ terminus. The second cleavage event removes an additional $8 \mathrm{kDa}$ from the $\mathrm{N}$ terminal piece, leaving the $33 \mathrm{kDa}$ kinase domain intact. While activity of the individual pieces was not determined directly in this study, analysis of FAK activity during apoptosis induced in Jurkat cells indicates that FAK activity decreases (Wen et al, 1997). It is not clear if this is due to loss of activity resulting from the observed cleavage events, or whether the decreased activity is a consequence of competitive/dominant negative effects of the generated fragments. The suggestion is, however, that FAK activity is compromised due to caspase-mediated proteolysis during certain forms of apoptosis. The loss of FAK activity may contribute to detachment of the dying cell from the substratum and to the morphological changes occurring during apoptosis, as well as to the loss of FAKmediated anti-apoptotic signals.

\section{DNA-dependent protein kinase (DNA-PK)}

DNA-PK is a predominantly nuclear serine/threonine kinase that is structurally related phosphatidylinositol 3-kinase and the ataxia telangiectasis gene product (Hungerford et al, 1996). DNA-PK is activated by double stranded DNA breaks, and is intimately involved in the repair of such breaks (see Han et al, 1996 for referenced reviews on this topic). DNA-PK is thought to be the product of the severe combined immunodeficiency (scid) gene, and animals mutated at this locus are deficient in repair of double stranded DNA breaks (Biedermann et al, 1991). Cells defective in this enzyme are sensitized to killing by ionizing radiation, while a cell line resistant to etoposide-induced apoptosis did not activate DNA-PK. Auto-reactive antibodies identified in human sera have been found to react with fragments of DNA-PK formed during apoptosis, and this may be an important component of autoimmune disease (Casciola-Rosen et al, 1995).

DNA-PK consists of a $460 \mathrm{kDa}$ catalytic subunit and the heterodimeric $\mathrm{Ku}$ regulatory subunit, made up of 70 - and $86-\mathrm{kDa}$ proteins. The catalytic subunit of DNA-PK has been shown to be proteolytically cleaved in response to inducers of apoptosis, including staurosporine and Fas (CasciolaRosen et al, 1995, 1996; Song et al, 1996; Han et al, 1996; McConnell et al, 1997). Cleavage of the $460 \mathrm{kDa}$ catalytic subunit results in the formation of a pair of $165 / 168 \mathrm{kDa}$ cleavage products (also described as $150 \mathrm{kDa}$ in some reports) and a single $240-250 \mathrm{kDa}$ fragment. Cleavage correlates with the onset of cell death and with activation of caspase-3 (CPP32). Proteolysis was inhibited in the 
presence of $1 \mu \mathrm{M}$ of the caspase-3 inhibitory peptide, AcDEVD-CHO, but not by up to $50 \mu \mathrm{M}$ Ac-YVAD-CHO. Proteolysis to generate the same fragments was observed in vitro in the presence of recombinant caspase-3, but not caspase-1 (ICE), caspase-4; or caspase-6. DNA-PK contains two potential caspase cleavage sites (aa 27092713 (DEVDN), and aa 2979-2983 (DWVGD)) which would generate fragments of the appropriate size as observed in these studies, and caspase action at these sites has been confirmed by $\mathrm{N}$-terminal sequence analysis of cleavage fragments (Song et al, 1996). It is of interest that the cleavage of DNA-PK during apoptosis correlates with the loss of its catalytic activity (Song et al, 1996; McConnell et al, 1997), suggesting that this may contribute to the DNA fragmentation that occurs during regulated cell death. In addition, DNA-PK normally phosphorylates and regulates the activity of the p53 tumor suppressor gene product. The loss of this activity is likely to contribute to dysfunctional regulation of cell cycle progression (LeesMiller et al, 1992; Shieh et al, 1997).

\section{Protein kinase $\mathbf{C}$ family members (PKC $\delta$ :PKC $\theta$ )}

The protein kinase Cs have long been known to be important components of intracellular signaling. This family of enzymes can be divided into the classical calciumdependent forms, and into calcium-independent novel and atypical groups. Two structurally related members of the novel group, $\operatorname{PKC} \delta$ and $\operatorname{PKC} \theta$, have been shown to be proteolytically cleaved during ionizing radiation-, Fas-, and TNF-induced apoptosis and ionizing radiation-, Ara-C-, etoposide-, cisplatinum-induced cell death, respectively (Emoto et al, 1995, 1996; Ghayur et al, 1996; Datta et al, 1997). Cleavage of the $78 \mathrm{kDa} \operatorname{PKC} \delta$ to a $40 \mathrm{kDa}$ fragment was inhibited by $B C L-2 / B C L-X_{L}$ expression and by treatment of cells with $10 \mu \mathrm{M}$ YVAD-CMK (DEVD peptides were not tested). Similarly, the $78 \mathrm{kDa}$ PKC $\theta$ cleavage to a $40 \mathrm{kDa}$ fragment was blocked by $B C L-X_{L}$, CrmA, or p35 expression. In vitro analysis demonstrated that PKC $\theta$ was cleaved specifically by caspase 3 , but not caspases 2, 4, 6, and 7 (Datta et al, 1997); PKC $\delta$ was cleaved by caspase 3, but not caspase 1 (Ghayur et al, 1996).

Proteolytic cleavage of both forms of PKC resulted in increased activity of the $40 \mathrm{kDa}$ kinase fragment, as assessed by phosphorylation of exogenous substrates by the partially purified kinase and by in-gel kinase assays, as well as by assay of the recombinant cleavage construct. This is likely a result of cleavage at aa327331 (DMQDN) in PKC $\delta$ (Ghayur et al, 1996) and aa351355 (DEVDK) in PKC $\theta$ (Datta et al, 1997) at the V3 region to form a constitutively active catalytic domain fragment. Overexpression of the constitutively active $\operatorname{PKC} \theta$ catalytic $40 \mathrm{kDa}$ fragment, but not the full length or a kinase-dead fragment, induced nuclear and DNA fragmentation concomitant with cell death. In contrast to the pro-apoptotic effects resulting from proteolytic cleavage of $\mathrm{PKC} \delta$ and PKC $\theta$, other work has shown that PKC $\zeta$ and $\mathrm{PKC} \lambda / l_{l}$ interact with Par-4 and abrogate the ability of Par-4 to induce apoptosis (Diaz-Meco et al, 1996), while the atypical $\mathrm{PKC}_{l}$ protects $\mathrm{K} 562$ leukemia cells against druginduced apoptosis (Murray and Fields, 1997), as does PKC $\beta$ II in HL60 cells (Whitman et al, 1997). It is also of interest that $\operatorname{PKC} \theta$ has recently been shown to be required for cell cycle progression and to modulate the formation of particular types of cytoskeletal structures (Tang et al, 1997).

A recent report has shown that the protein kinase Crelated kinase 2 (PRK2 kinase) is proteolyzed by caspase 3 at two sites in vitro, as well as during apoptosis induced by Fas or staurosporine (Cryns et al, 1997). Both cleavage sites in vivo were within the regulatory domain of this serine/threonine kinase, suggesting its activity may be upregulated during apoptosis. It is of particular significance that PRK2 kinase has been shown to bind and be stimulated by the small GTPases Rac and Rho (Vincent and Settleman, 1997). PRK2 appears to be involved in cytoskeletal regulation by these GTPases, and it is interesting to speculate that activation of both PRK2 and PAK2 by caspases enables them to exert important regulatory influences on the cytoskeletal dynamics of the apoptotic cell.

\section{PITSLRE Kinase}

PITSLRE $\beta$ | is a $58 \mathrm{kDa}$ member of a family of p34cdc2related serine/threonine kinases which are expressed in both tissue specific- and ubiquitous fashion (Lahti et al, 1995 and references therein). Expression of PITSLRE $\beta$, induces teleophase delay, abnormal segregation of chromosomes and decreased growth rates due to apoptosis in Chinese hamster ovary cells. Apoptosis can be induced by ectopic expression of an amino-terminal (aa 1-74) deleted mutant containing an active catalytic domain. The levels of PITSLRE message and activity were observed to increase in Fas-stimulated Jurkat $T$ cells. This was associated with the formation of $43-50 \mathrm{kDa} C$ terminal PITSLRE catalytic fragments. Generation of these cleavage products was inhibited, along with Fas-induced cell death, by treatment with TPCK Curiously, cysteine protease inhibitors were reported to have no effect on either Fas-induced PITSLRE cleavage or cell death in these studies. However, recent work has shown that PITSLRE is cleaved during TNF-induced apoptosis, and that cleavage is sensitive to CrmA and BCL-2 (Beyaert et al, 1997). Both ICE/caspase-1 and CPP32/caspase-3 were able to produce cleavage of PITSLRE kinase in vitro at Asp 393 within the sequence YVPDS to generate the $43 \mathrm{kDa} C$ terminal fragment. In vivo analysis in caspase-1 deficient cells indicated that cleavage of PITSLRE was normal, suggesting that caspase- 3 may be the physiologically relevant protease. Removal of portions of the PITSLRE regulatory $\mathrm{N}$ terminus are known to increase kinase activity and increased activity is observed during apoptotic responses in several cell lines. Furthermore, the $\mathrm{N}$ terminus contains two nuclear localization signals and a region capable of binding to $\mathrm{SH} 2$ domains, suggesting that cleavage during apoptosis may be a mechanism to modulate localization and/or interactions with other proteins, as well as activity. 


\section{Calmodulin-dependent protein kinase II (CaM KII)}

Both tumor necrosis factor and UV light rapidly stimulate calcium independent CaM KII activity in U937 and several other cell lines (Wright et al, 1997). Cell lines resistant to TNF- or UV-induced apoptosis, such as K562 cells, do not activate CaM KII. Calcium independent CaM KII activation was blocked by VAD-fmk and TPCK, suggesting that proteolysis was required for the activation process. Proteolytic cleavage to an active catalytic fragment by caspases was implied, but not demonstrated by these data. Activation of this enzyme may be of interest, as two mechanistically distinct inhibitors of CaM KII block DNA fragmentation and cell death in U937 cells. CaM KII has also been implicated in regulation of processes as diverse as ion channel function, calcium homeostasis and cytoskeletal regulation.

\section{Raf-1, Akt}

Survival signals initiated by both Raf-1, through the ERK MAP kinase pathway, and Akt, through phosphorylation of $B A D$, have protective effects against apoptosis initiated by a variety of agents (see Discussion above). It has been recently reported that both Raf-1 and Akt are proteolytically degraded in a caspase-dependent (i.e., Ac-YVAD-CMKand $B c l x_{L}$-dependent) manner (Widmann et al, 1998). The caspase responsible for these cleavages and the site(s) of cleavage are unknown. Degradation of both enzymes occurred relatively late during the apoptotic response, but correlated with loss of both Raf- 1 and Akt activity. Thus, caspase action may specifically turn off these survival pathways that could otherwise interfere with the ongoing apoptotic response.

\section{Conclusions}

It is remarkable that an increasing number of kinases capable of regulating intracellular signaling are targets for caspases during the cell death program. Certainly these kinases are at least capable of modulating the apoptotic responsiveness of the cell, and it may be hypothesized that they may additionally serve as critical control elements for regulating and coordinating the complex biochemical and morphological changes accompanying apoptotic death. It is interesting to speculate that, just as activation of kinase signaling pathways in response to hormones and other physiological stimuli regulate cell growth and proliferation through their action on specific regulatory targets, the activation (or inhibition) of specific kinases through their irreversible proteolytic cleavage by caspases might control a specific sequence of events that produces the well-known apoptotic program (Figure 2). Thus, the concept of a 'death by a thousand cuts' resulting from the promiscuous action of caspases (Martin and Green, 1995), may be misleading; rather, 'death via a specific series of caspase-initiated kinase signaling events' may be more fundamental to the controlled apoptotic responses which lead to the orderly demise of the cell. Indeed, the sensitivity of apoptotic responses to
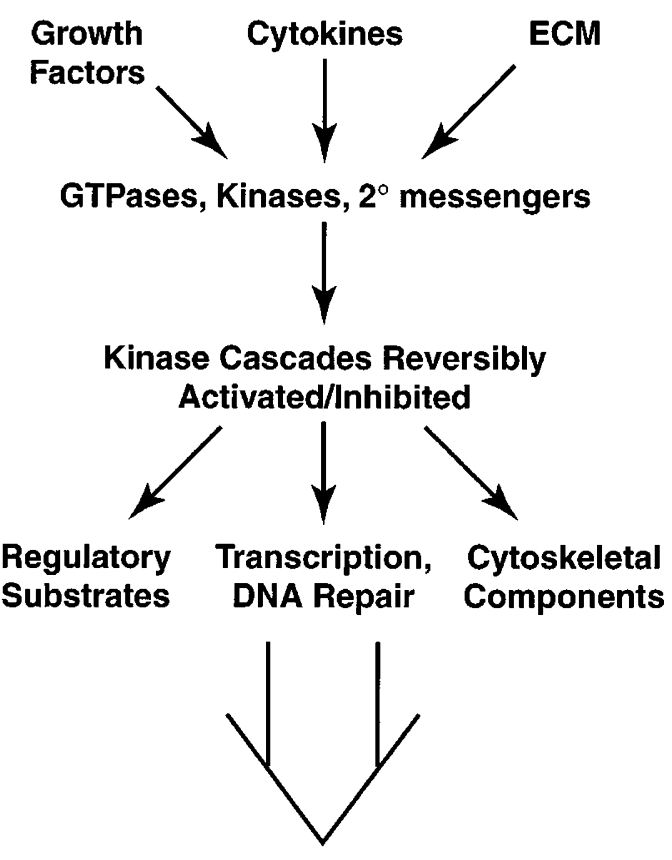

Proliferation
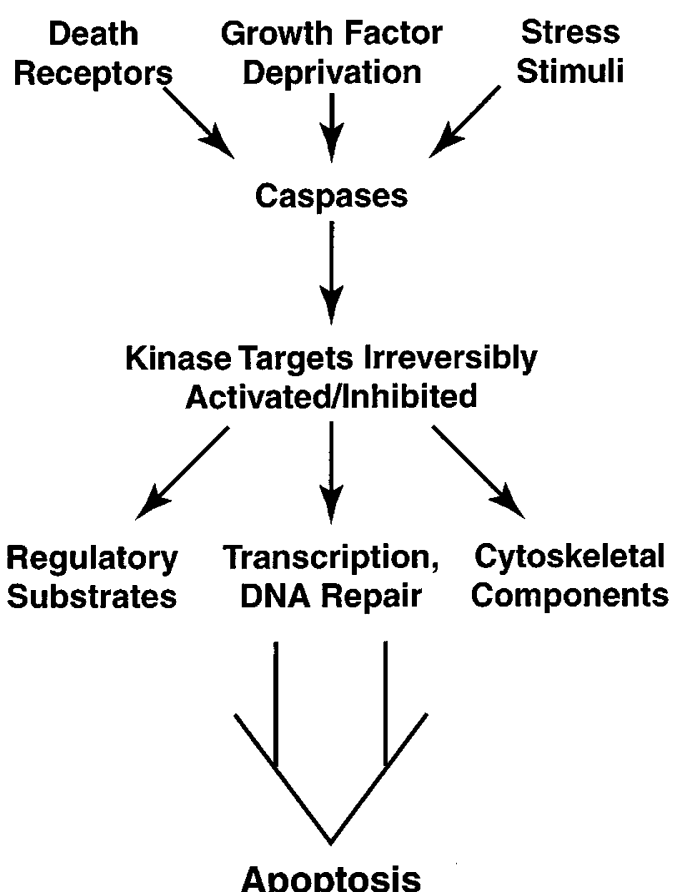

Figure 2 Parallels in the kinase signaling pathways that regulate cell proliferation and those that may regulate the cell death program. Just as kinase activation by extracellular signals controls cell growth, kinase activation by caspases may initiate and regulate a specific series of cellular events that lead to the characteristic responses of the apoptotic cell. ECM, extracellular matrix 
protein kinase inhibitors and protein phosphatases suggests that there may be some truth to this hypothesis. Certainly, additional studies to identify kinase targets for caspases and to determine their specific contributions to the apoptotic program are warranted. An understanding of the mechanisms through which the kinases serving as caspase targets are acting to regulate the apoptotic program should lead to new insights into the underlying biochemical mechanisms involved in controlling normal and pathological cell death.

\section{Note added in proof}

A recent paper describes the PAK-related kinase MST1 as an additional caspase target during staurosporine- and Fas-induced apoptotic death in BJAB human B lymphoma cell lines

\section{Acknowledgements}

The contributions of my associates, including Drs. Frank Zenke, Thomas Rudel, Tsung-Hsien Chuang, Maria C. Subauste, Klaus Hahn and Ulla G. Knaus are acknowledged. Our work is supported by NIH grants GM55322 and GM39434. Excellent editorial assistance was provided by Ms. Antonette Lestelle.

\section{References}

Beyaert R, Kidd W, Cornelis S, Van de Craen M, Denecker G, Laliti JM, Gururajan R, Vandenabeele P and Fiers W (1997) Cleavage of PITSLRE kinases by ICE/ CASP-1 and CPP32/CASP-3 during apoptosis induced by tumor necrosis factor. J. Biol. Chem. 272: 11694-11697

Biedermann KA, Sun J, Giaccia AJ, Tosto LM and Brown JM (1991) SCID mutation in mice confers hypersensitivity to ionizing radiation and a deficiency in DNA double-strand break repair. Proc. Natl. Acad. Sci. USA 88: 1394-1397

Bokoch GM, Wang Y, Bohl BP, Sells MA, Quilliarn LA and Knaus UG (1996) Interaction of the Nck adapter protein with p21-activated kinase (PAK1). J. Biol. Chem. 271: 25746-25749

Brzeska H, Knaus UG, Wang Z, Bokoch GM and Korn ED (1997) p21-activated kinase (PAK) has substrate specificity similar to Acanthamoeba myosin I heavy chain kinase and activates Acanthanweba myosin I. Proc. Natl. Acad. Sci. USA 94: 1092-1095

Cardone MH, Salvesen GS, Widinann C, Johnson G and Frisch SM (1997) The regulation of anoikis: MEKK-1 activation requires cleavage by caspases. Cell 90: $315-323$

Casciola-Rosen LA, Anhalt GJ and Rosen A. (1995) DNA-dependent protein kinase is one of a subset of autoantigens specifically cleaved early during apoptosis. J. Exp. Med. 182: 1625-1634

Casciola-Rosen LA, Nicholson DW, Chong T, Rowan KR, Thornberry NA, Miller DK and Rosen A. (1996) Apopain/CPP32 cleaves proteins that are essential for cullular repair: a fundamental principle of apoptotic death. J. Exp. Med. 183: 1957- 1964

Chen CS, Mrksich M, Huang S, Whitesides M and Ingber DE (1997) Geometric control of cell life and death. Science 276: $1425-1428$

Chinnalyan AM and Dixit VM (1996) The cell death machine. Curr. Bio. 5: 555-562

Chuang T, Hahn KM, Danley DE and Bokoch GM (1997) The small GTPase Cdc42 initiates an apoptotic signaling pathway in Jurkat T lymphocytes. Mol. Biol. Cell 8: $1687-1698$

Cohen O, Feinstein E and Kimchi A (1997) DAP-kinase is a $\mathrm{Ca}^{2+} /$ calmodulindependent, cytoskeletal-associated protein kinase, with cell death-inducing functions that depend on its catalytic activity. EMBO J. 16: 998-1008

Cosulich S and Clarke P. (1996) Apoptosis: does stress kill? Curr. Bio. 6: 1586-1588

Crouch DH, Fincham VJ and Frame MC (1996) Targeted proteolysis of the foca adhesion kinase pp125 ${ }^{\mathrm{FAK}}$ during c-Myc-induced apoptosis is suppressed by integrin signalling. Oncogene 12: 2689-2696
Cryns VL, Byun Y, Rana A, Mellor H, Lustig KD, Ghanem L, Parker PJ, Kirschner MW and Yuan J (1997) Specific proteolysis of the kinase protein kinase Crelated kinase 2 by Caspase-3 during apoptosis. J. Biol. Chem. 272: $29449-$ 29453

Cullen BR (1996) HIV-1: Is Nef a PAK animal? Curr. Bio. 6: 1557-1559

Datta R, Kojima H, Yoshida K and Kufe D (1997) Caspase-3-mediated cleavage of protein kinase $C \Phi$ in induction of apoptosis. J. Biol. Chem. 272: 20317-20320

Datta SR, Dudek H, Tao X, Masters S, Fu H, Gotoh Y and Greenberg ME (1997) Akt phosphorylation of BAD couples survival signals to the cell-intrinsic death machinery. Cell 91: 231-241

Deiss LP, Feinstein E, Berissi H, Cohen O and Kimchi A (1995) Identification of a novel serinelthreonine kinase and a novel $15-\mathrm{kD}$ protein as potential mediators of the $\gamma$ interferon-induced cell death. Genes \& Devel. 9: 15-30

del Peso L, Gonzaltz-Garcia M, Page C, Herrera R and Nunez G (1997) Interleukin-3induced phosphorylation of BAD through the protein kinase Akt. Science 278 : $687-689$

Dharmawardhane S, Sanders LC, Martin SS, Daniels RH and Bokoch GM (1997) Localization of p21-activated kinase 1 (PAK1) to pinocytic vesicles and cortical actin structures in stimulated cells. J. Cell Biol. 138: 1265-1278

Diaz-Meco MT, Municio MM, Frutos S, Sanchez P, Lozano J, Sanz L and Moscat J (1996) The product of par-4, a gene induced during apoptosis, interacts selectivity with the atypical isoforms of protein kinase $\mathrm{C}$. Cell 86: 777-786

Eischen CM, Dick G and Uibson PJ. (1994) Tyrosine kinase activation provides an early and requisite signal for Fas-induced apoptosis. J. Immunol. 153: 19471954

Ellis RE, Yuan J and Horvitz HR (1991) Mechanisms and functions of cell death. Ann. Rev. Cell Biol. 7: 663-698

Emoto Y, Manome Y, Meinhardt G, Kisaki H, Kharbanda S, Robertson M, Ghayur T, Wong WW, Kamen R, Weichselbaum R et al (1995) Proteolytic activation of protein kinase $C \delta$ by an ICE-like protease in apoptotic cells. EMBO J. 14:61486156

Emoto Y, Kisaki H, Manome Y, Kharbanda S and Kufe D (1996) Activation of protein kinase $\mathrm{C} \delta$ in human myeloid leukemia cells treated with 1- $\beta$-D-arabinofuranosyleytosine. Blood 5: 190-1996

Fanger GR, Johnson L and Johnson GL (1997) MEK kinases are regulated by EGF and selectively interact with Rac/Cdc42. EMBO J. 16: 4961-4972

Frisch SM, Wori K, Kelaita D and Sicks S (1996) A role for Jun-N-terminal kinase in anoikis: suppression by bcl-2 and crmA. J. Cell Biol. 135: 1377-1382

Frisch SM and Francis H (1994) Disruption of epithelial cell-matrix interactions induces apoptosis. J. Cell Biol. 124: 619-626

Gajewski TF and Thompson CB (1996) Apoptosis meets signal transduction: elimination of a BAD influence. Cell 87: $589-592$

Galisteo M, Chernoff J, Su Y, Skolnik EY and Schlessinger J (1996) The adaptor protein Nck links recepter tyrosine kinases with the scrine-threonine kinase Pak1. J. Biol.Chem. 271: 20997-21000

Ghayur T, Hugunin M, Talanian RV, Ratnofsky S, Quinlan C, Emoto Y, Pandey P, Datta R, Fluang Y, Kharbanda S et al (1996) Proteolytic activation of protein kinase $C \delta$ by an ICE/CED 3-like protease induces characteristics of apoptosis. J. Exp. Med. 184: 2399-2404

Graves JD, Gotoh Y, Draves KE, Ambrose D, Han DKM, Wright M, Chernoff J, Clark EA and Krebs EG (1998) EMBO J. 17: 2224-2234

Han Z, Malik N, Carter T, Westley HR, Wyche JH and Hendrickson EA (1996) DNAdependent protein kinase is a target for a CPP32-like apoptotic protease. J. Biol. Chem. 271: 25035-25040

Holmström TH, Chow SC, Elo I, Coffey ET, Orrenius S, Sistonen L and Eriksson JE (1998) Suppression of Fas/APO- 1 -mediated apoptosis by mitogen-activated kinase signaling. J. Immunol. 160: 2626-2636

Hueber A, Zörnig M, Lyon D, Suda T, Nagata S and Evan GI (1997) Requirement for the CD95 receptor-ligand pathway in c-Myc-induced apoptosis. Science 278 : $1305-1309$

Hungerford JE, Compton MT, Matter ML, Hoffstrom BG and Otey CA (1996) Inhibition of pp $125^{\mathrm{FAK}}$ in cultured fibroblasts results in apoptosis. J. Cell Biol. 135: 13831390

Hunter T (1997) Oncoprotein networks. Cell 86: 333-346

Inbal B, Cohen O, Polak-Charcon S, Kopolovic J, vadai Z, Eisenbach L and Kimchi A (1997) DAP kinase links the control of apoptosis to metastasis. Nature 390: 180183

Jacobson MD, Well M and Ruff MC (1997) Programmed cell death in animal development. Cell 88: $347-354$ 
Jin S, Inoue S and Weaver DT (1997) Functions of DNA dependent protein kinase. Cancer Surv. 29: 221-261

Johnson NL, Gardner AM, Diener KM, Lange-Carter CA, Gleavy J, Jarpe MB, Minden A, Karin M, Zon LI and Johnson GL (1996) Signal transduction pathways regulated by mitogen-activated/extracellular response kinase kinase kinase induce cell death. J. Biol. Chem. 271: 3229-3237

King KL and Cidlowski JA (1995) Cell cycle and apoptosis: common pathways in life and death. J. Cell Biochem. 58: 175-180

Knaus UG, Morris S, Dong H, Chernoff J and Bokoch GM (1995) Regulation of human leukocyte $\mathrm{p} 21$-activated kinases through $\mathrm{G}$ protein-coupled receptors. Science 269: $221-223$

Lahti JM, Xiang J, Heath LS, Dampana D and Kidd VJ (1995) PITSLRE protein kinase activity is associated with apoptosis. Mol. Cell Biol. 15: 1-11

Lee N, MacDonald H, Reinhard C, Halenbeck R, Roulston A, Shi T and Williams LT (1997) Activation of hPAK65 by caspase cleavage induces some of the morphological and biochemical changes of apoptosis. Proc. Natl. Acad. Sci. USA 94: $13642-13647$

Lees-Miller S, Sakaguchi K, Ullrich SJ, Appella E and Anderson CW (1992) Human DNA-activated protein kinase phosphorylates serines 15 and 37 in the amino-terminal transactivation domain of human p53. Mol. Cell Bio. 12: 5041-5049

Leeuw T, Forrest-Lieuvin A, Wu C, Chenevert J, Clark K, Whiteway M, Thomas DY and Leberer $E$ (1995) Pheremone response in yeast: association of bemlp with proteins of the MAP kinase cascade and actin. Science 270: 1210-1213

Majno $G$ and Joris I (1995) Apoptosis, oncosis and necrosis. An overview of cell death. Am. J. Pathol. 246: 3-15

Manser E, Leung T, Salihuddin H, Zhao Z and Lim L (1994) A brain serine/treonine protein kinase activated by $\mathrm{Cdc42}$ and Racl. Nature $367: 40-46$

Manser E, Huang H, Lou T, Chen X, Dong J, Leung T and Lim L (1997) Expression of constitutively active a-PAK reveals effects on the kinase on actin and focal complexes. Mol. Cell Biol. 17: 1129-1143

Martin GA, Bollag G, McCormick F and Abo A (1995) A novel serine kinase activated by racl/CDC42Hs-dependent autophosphorylation is related to PAK65 and STE20. EMBO J. 14: 1970-1978

Martin SJ and Green DR (1995) Protease activation during apoptosis: death by a thousand cuts? Cell 82: 349-352

Mathias S, Dressier KA and Kolesnick RN (1991) Characterization of a ceramideactivated protein kinase: stimulation by tumor necrosis factor $\alpha$. Proc. Natl. Acad. Sci. USA 88: $10009-10013$

Maundrell K, Antonsson B, Magnenat E, Cammps M, Muda M, Chabert C, Gillieron C, Boschert U, Vial-Knecht E, Martinou J et al (1997) Bcl-2 undergoes phosphorylation by c-Jun $\mathrm{N}$-terminal kinase/stress-actived protein kinases in the presence of the constitutively active GTP-binding protein Rac1. J. Biol. Chem. 272: 25238-25242

McConnell KR, Dynan WS and Hardin JA (1997) The DNA-dependent protein kinase catalytic subunit (p460) is cleaved during Fas-mediated Apoptosis in Jurkat cells. J. Immunol. 158: 2082-2089

Meredith JE, Fazeli B and Schwartz MA (1993) The extracellular matrix as a cell survival factor. Mol. Biol. Cell 4: 953-961

Morana SJ, Wolf CM, Ji J, Reynolds JE, Brown MK and Eastman A (1996) The involvement of protein phosphatases in the activation of ICD/CED-3 protease, intracellular acidification, DNA digestion, and apoptosis. J. Biol. Chem 271: $18263-18271$

Murray NR and Fields AP (1997) Atypical protein kinase C iota protects human leukemia cells against drug-induced apoptosis. J. Biol. Chem. 272: 27521 27524

Nicholson DW and Thomberry NA (1997) Caspases: killer proteases. Trends Biochem. Sci. 22: 299-306

Park J, Kim I, Oh YJ, Lee K, Han P and Choi E (1997) Activation of c-Jun N-terminal kinases antagonizes an anti-apoptotic action of Bcl-2. J. Biol. Chem. 272: $16725-16728$
Ramos E, Wysolmerski RB and Masaracchia RA (1997) Myosin phosphorylation by human cdc42-dependent S6/H4 kinase/yPAK from placenta and lymphoid cells. Receptors and Signal Trans. 7: 99-110

Rosen A and Casciola-Rosen L (1997) Macromolecular substrates for the ICE-like proteases during apoptosis. J. Cell Biol. 64: 50-54

Rudel T, Zenke FT, Chuang T and Bokoch GM (1998) p21-Activated kinase (PAK) is required for Fas-induced JNK activation in Jurkat cells. J. Immunol. 160: 7-11

Rudel T and Bokoch GM (1997) Membrane and morphological changes in apoptotic cells regulated by caspase-mediated activation of PAK2. Science 276: 15711574

Sato T, Irie S, Kitada S and Reed X (1995) FAP-1: a protein tyrosine phosphatase that associates with FAS. Science 268: 411-415

Saure S, Vigneron S, Doree Mand Morin N (1997) A member of the Ste20/PAK family of protein kinases is involved in both arrest of Xenopus Oocytes and $\mathrm{G}_{2} /$ prophase of the first meiotic cell cycle and in prevention of apoptosis. EMBO J. 16: $5550-$ 5561

Sells MA, Knaus UG, Ambrose D, Bagrodia S, Bokoch GM and Chernoff J (1997) Human p21 activated kinases regulate actin reorganization in mammalian cells. Curr. Bio. 7: 202-210

Sells MA and Chernoff J (1997) Emerging from the Pak: the p21-activated protein kinase family. Trends Cell Biol. 7: 162-167

Shieh SY, Ikeda M, Taya Y and Prives C (1997) DNA damage-induced phosphorylation of p53 alleviates inhibition by MDM2. Cell 91: 325-334

Song Q, Lees-Miller SP, Kumar S, Zhang N, Chan DW, Smith GCM, Jackson SP, Alnemri ES, Litwack G, Khanna KK et al (1996) DNA-dependent protein kinase catalytic subunit: a target for an ICE-like protease in apoptosis. EMBO J. 15: $3238-3246$

Tang S, Morgan KG, ParkerC and Ware JA (1997) Requirementfor protein kinase C $\Phi$ for cell cycle progression and formation of actin stress fibers and filopodia in vascular endothelial cells. J. Biol. Chem. 272: 28704-28711

Tuazon PT and Traugh JA (1984) Activation of actin-activated ATPase in smooth muscle by phosphorylation of myosin light chain with protease-activated kinase I. J. Biol. Chem. 259: 541-546

Vincent S and Settleman J (1997) The PRK2 Kinase is a potential effector target of both Rho and Rac GTPases and regulates actin cytoskeletal organization. Mol. Cell Biol. 17: 2247-2256

Wen L, Fagrni JA, Troie S, Guan J, Orth K and Rosen GD (1997) Cleavage of focal adhesion kinase by caspases during apoptosis. J. Biol. Chem. 272: $26056-$ 25061

Whitman SP, Civoli F and Daniel LW (1997) Protein kinase C $\beta$ II activation by 1- $\beta$-Darabinofuranosylcytosine is antagonistic to stimulation of apoptosis and $\mathrm{BCl}-2 \alpha$. down-regulation. J. Biol. Chem. 272: 23481-23484

Whyte M (1996) ICE/CED-3 proteases in apoptosis. Trends Cell Biol. 6: 245-248

Widmann C, Gibson S and Johnson GL (1998) Caspase-dependent cleavage of signaling proteins during apoptosis. A turn-off mechanism for anti-apoptotic signals. J. Biol. Chem. 273: 7141-7147

Wright SC, Schellenberger U, Ji L, Wang H and Larrick JW (1997) Calmodulindependent protein kinase II mediates signal transduction in apoptosis. FASEB J. 11: $843-849$

Wu C, Lee S, Furmaniak-Kazmierzak E, Coté GP, Thomas DY and Leberer E (1996) Activation of Myosin-I by members of the Ste20p protein kinase family. J. Biol. Chem. 271: 31787-31790

Wyllie AH ed (1997) Apoptosis. British Medical Bulletin 53, The Dorset Press, Dorchester.

XiaZ, Dickens M, Raingeaud J, Davis RJ and Greenberg ME (1995) Opposing effects of ERK and JNK-p38 MAP kinases on apoptosis. Science 270: 1326-1331

Yang X, Khosravi-FarR, Chang HY and Baltimore D (1997) Daxx, a novel Fas-binding protein that activates JNK and apoptosis. Cell 89: 1067-1076 